\title{
Erratum to: Sorption of U(VI) onto a decarbonated calcareous soil
}

\author{
Yuying Zhang • Haogui Zhao • Qiaohui Fan • \\ Xiaobei Zheng $\cdot$ Ping Li $\cdot$ Shengping Liu $\cdot$ \\ Wangsuo Wu
}

Published online: 3 April 2013

(C) Akadémiai Kiadó, Budapest, Hungary 2013

\section{Erratum to: J Radioanal Nucl Chem (2011) 288:395-404 \\ DOI 10.1007/s10967-010-0948-z}

In looking through our published article, we found that there is a mistake in Fig. 14, where a wrong legend was used. The authors regret very much that the incorrect version of Fig. 14 appeared in the original manuscript. The correct version of the Fig. 14 is presented here.
The online version of the original article can be found under doi:10.1007/s10967-010-0948-z.

Y. Zhang · H. Zhao · Q. Fan $(\bowtie) \cdot$ X. Zheng $\cdot$ P. Li ·

S. Liu · W. Wu ( $\square)$

Radiochemistry Laboratory, Lanzhou University,

Lanzhou 730000, China

e-mail: fanqiaohui@gmail.com

W. Wu

e-mail: wuws@lzu.edu.cn

W. Wu

State Key Laboratory of Applied Organic Chemistry,

Lanzhou University, Lanzhou, China

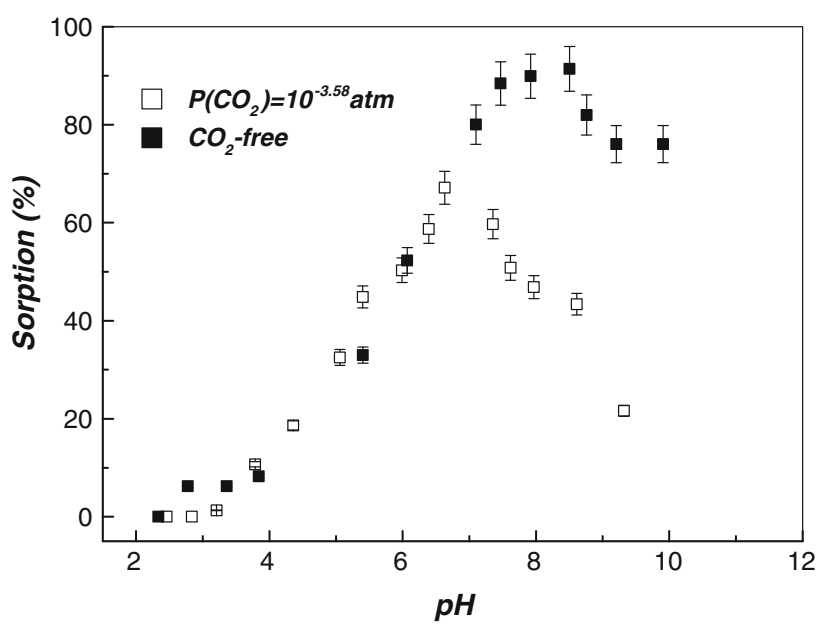

Fig. 14 Effect of $\mathrm{CO}_{2}$ on U(VI) sorption on DCS as a function of $\mathrm{pH}$ values. $C\left[\mathrm{UO}_{2}{ }^{2+}\right]_{\text {initial }}=2.86 \times 10^{-5} \mathrm{~mol} / \mathrm{L}, I=0.05 \mathrm{~mol} / \mathrm{L}$ $\mathrm{NaClO}_{4}, m / V=0.4 \mathrm{~g} / \mathrm{L}, T=25 \pm 1{ }^{\circ} \mathrm{C}$. $\mathbf{\square}: \mathrm{CO}_{2}$-free, $\square: P\left(\mathrm{CO}_{2}\right)=$ $10^{-3.58} \mathrm{~atm}$ 